\title{
El movimiento consciente en el estudio de la técnica para guitarra
}

\author{
The conscious movement in the study \\ of guitar technique
}

Nelson Gómez González*

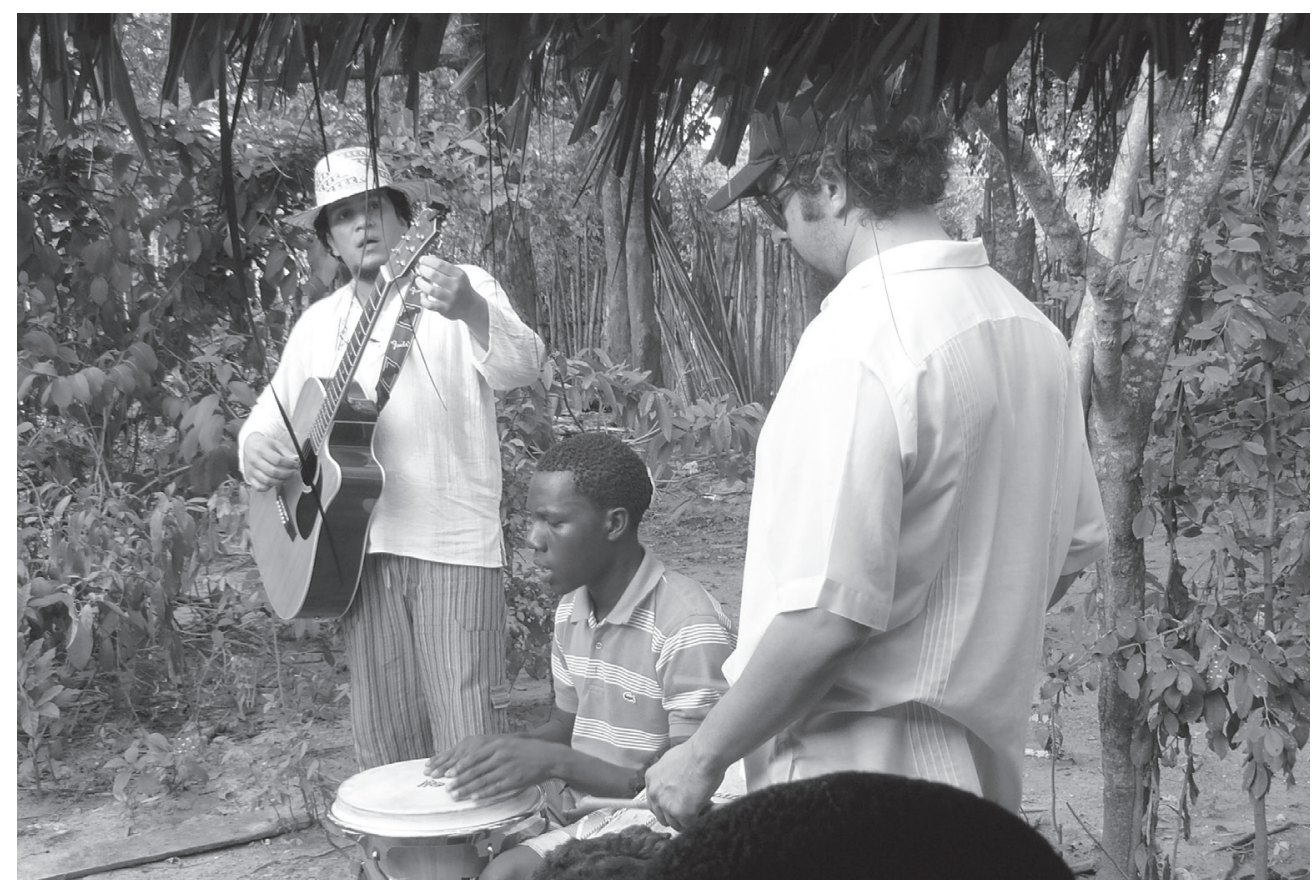

\section{Resumen}

Algunos métodos para guitarra proponen el estudio de la técnica a través del planteamiento de ejercicios mecánicos, escritos en forma secuencial y que deben ser ejecutados repetitivamente con el fin de lograr un objetivo motor que permita el mejor desempeño de las manos en la interpretación de una pieza musical. Este artículo plantea la posibilidad de abordar estos métodos a partir del manejo consciente del movimiento, basado en conceptos fundamentales relacionados con el funcionamiento neuromotor y desarrollado en estudios realizados por diferentes intérpretes de guitarra e investigadores de neurociencia.

Palabras clave: movimiento, neurociencia, técnica, guitarra.

Citar este artículo como: Gómez González, N. (2017). El movimiento consciente en el estudio de la técnica para guitarra. Revista Papeles, 9(18), 45-55.

Fecha de recibido: 13 de mayo de 2017

Fecha de aceptación: 21 de julio de 2017

* Guitarrista del Conservatorio de la Universidad Nacional de Colombia, Magíster en Estudios Musicales de la Universidad Central. Docente universitario. Correo electrónico: nelsongomezg7@gmail.com 


\begin{abstract}
Some methods for guitar propose the study of the technique through the presentation of mechanical exercises, written sequentially and that must be executed repetitively in order to achieve a motor target that allows the best potential of the hands in the performance of a musical piece. This article proposes the possibility of approaching these methods based on the conscious management of movement and on fundamental concepts related to neurological functioning and developed in studies carried out by different guitar players and neuroscience researchers.
\end{abstract}

Key words: movement, neuroscience, technique, guitar.

\title{
Introducción
}

Este documento tiene como objetivo presentar algunas metodologías de estudio de la técnica guitarrística que permitan un mejor rendimiento y eficacia en la interpretación mecánica de las obras a través del manejo consciente del movimiento, el reconocimiento e interiorización de conceptos fundamentales relacionados con el aspecto psicomotor y el funcionamiento neuromotor. Es necesario entender que no se abordará el aspecto estilístico de acuerdo con las diferentes épocas, géneros y compositores sino la forma de afrontar dificultades que se presenten en las piezas desde el punto de vista de los recursos técnicos necesarios para llevar a buen fin el proceso motor pertinente para la ejecución de las mismas por medio de la concienciación muscular, ordenamiento del pensamiento y manejo consciente, controlado y dirigido del movimiento. Esta reflexión nace de la propia experiencia como intérprete y pedagogo y del análisis de varios documentos fundamentalmente de los autores Eduardo Fernández (guitarrista uruguayo) y Rodolfo Llinás (neurocientífico colombiano).

Generalmente, en los primeros años de estudio del instrumento nos vemos enfrentados a varias situaciones para las que no estamos preparados o no imaginamos que llegaran a ser tan complejas, tales como adoptar la posición con el instrumento, la colocación de las manos en el diapasón, tocar una escala, un arpegio o un ligado. Además, empezamos a escuchar sobre conceptos aparentemente sencillos en su comprensión (no tanto en su aplicación y afianzamiento) como relajar, pulsar, respiración, sonido, proyección, solo por citar algunos ejemplos, pero aún aquí en este punto no somos conscientes, la mayoría de las veces, de los mecanismos necesarios para hacerlos correctamente. Otro aspecto con el que muchos se sentirán identificados es la enorme cantidad de ejercicios técnicos y estudios de todo tipo cuyo objetivo principal es resolver dificultades específicas, comenzando así el montaje de pasajes musicales cortos o extensos sin tener en cuenta los elementos y procesos fundamentales del funcionamiento cerebral en el movimiento que nos permita llegar a las metas propuestas, utilizando generalmente la metodología "ensayo-error", repitiendo movimientos una y otra vez hasta lograr el objetivo musical, aunque no siempre con éxito, de forma aparentemente controlada. De este modo, pretendemos aproximarnos a un concepto musical determinado por nuestra experiencia auditiva delegando la responsabilidad a dichas repeticiones sistemáticas, es decir: “ilo repito hasta que me salga!”, una frase que demandará gran trabajo, extensas jornadas de estudio, poca efectividad y generalmente gran frustración. No es de sorprendernos que este tipo de procesos metodológicos sucedan, ya que si la naturaleza de la mente depende de 
un proceso evolutivo, ella intentará resolver las dificultades de la misma forma como ha logrado funciones motrices tan complejas como caminar e incluso caminar sin estrellarse. Según Llinás: "La naturaleza de la mente debe entenderse con base en su origen, en el proceso de su desarrollo, que emana del perenne mecanismo biológico de ensayo y error" (Llinás, 2003). El estudio de las técnicas pura y aplicada es necesario para el desarrollo como músicos porque nos permite llegar más fácilmente a un objetivo musical determinado por el género, el estilo, la época o el compositor. El problema que pretendo abordar no es el objetivo musical sino los medios para conseguir mejores y más satisfactorios resultados técnicos. No digo que no sea necesario repetir movimientos, no, es necesario repetir... pero no tanto, se puede ahorrar tiempo y energía utilizando mecanismos coherentes con el funcionamiento y proceso lógico del cerebro para producir movimiento.

No digo que no sea necesario repetir movimientos, no, es necesario repetir... pero no tanto, se puede ahorrar tiempo y energía utilizando mecanismos coherentes con el funcionamiento y proceso lógico del cerebro para producir movimiento.

\section{Procesos neurocognitivos}

Será necesario en este punto aclarar algunos aspectos relacionados con los estados funcionales del cerebro, la mente y las imágenes sensomotoras, que son pertinentes para el desarrollo y la concreción de estas reflexiones. Para Llinás:

Desde mi perspectiva monista, el cerebro y la mente son eventos inseparables. Igual importancia que lo anterior tiene entender que la "mente", o el estado mental, constituye uno de los estados funcionales generados por el cerebro. Los estados mentales conscientes pertenecen a una clase de estados funcionales del cerebro en los que se generan imágenes cognitivas sensomotoras, incluyendo la autoconciencia. Al hablar de imágenes sensomotoras, no sólo me refiero a las visuales, sino a la conjunción o enlace de toda información sensorial capaz de producir un estado que pueda resultar en una acción. (p. 1)
El cerebro cumple una serie de funciones organizadas dentro de las que convergen la percepción a través de los sentidos, interpretación de dicha imagen sensomotora (ya sea un sonido, un color, una textura), para luego crear un estado mental que genere una idea o un movimiento. Centraré mi atención fundamentalmente en los sentidos visual, auditivo y táctil, dentro del cual incluyo la consciencia muscular, es decir, percepción y control del músculo o grupo de músculos que participan en un movimiento determinado, ya que son los sentidos de mayor aplicación en la interpretación de un instrumento musical que se complementan e interactúan entre sí, creando una red de información que el cerebro transformará en movimiento para llegar a un concepto sonoro. En el siguiente cuadro veremos algunas de las acciones más comunes que enfrenta un instrumentista y el desempeño de los sentidos en cada una de ellas. 
Tabla 1. Discriminación sensorial asociada a conceptos interpretativos

\begin{tabular}{|l|c|c|c|}
\hline \multicolumn{1}{|c|}{ Conceptos } & Visual & Auditivo & Táctil \\
\hline Posición del cuerpo & $\mathrm{X}$ & $\mathrm{X}$ \\
\hline Colocación de las manos & $\mathrm{X}$ & $\mathrm{X}$ \\
\hline Acción muscular & $\mathrm{X}$ & $\mathrm{X}$ \\
\hline Reconocimiento y evaluación de tensiones & $\mathrm{X}$ & $\mathrm{X}$ \\
\hline Desplazamientos en el diapasón & $\mathrm{X}$ & $\mathrm{X}$ \\
\hline Relajación & $\mathrm{X}$ & $\mathrm{X}$ \\
\hline Puntos de contacto con el instrumento & $\mathrm{X}$ & $\mathrm{X}$ \\
\hline Puntos de contacto de los dedos en el diapasón & $\mathrm{X}$ & $\mathrm{X}$ \\
\hline Reconocimiento de alturas & & $\mathrm{X}$ & \\
\hline Reconocimiento de timbres & & $\mathrm{X}$ & \\
\hline Sonido & & $\mathrm{X}$ & $\mathrm{X}$ \\
\hline Polifonía & & $\mathrm{X}$ & \\
\hline Percepción de concepto sonoro & & $\mathrm{X}$ & \\
\hline Apreciación estética de estilos & & $\mathrm{X}$ & \\
\hline Concepto sonoro & $\mathrm{X}$ & $\mathrm{X}$ & $\mathrm{X}$ \\
\hline Técnica & $\mathrm{X}$ & $\mathrm{X}$ \\
\hline Ejecución y apropiación de un concepto sonoro & & $\mathrm{X}$ \\
\hline
\end{tabular}

Fuente: elaboración propia.

Como podemos apreciar, los conceptos técnicos e interpretativos (movimiento) de un concepto sonoro (imagen sensomotora) abarcan y requieren el mayor potencial de los sentidos, teniendo, claro, que ambos, tanto técnica como concepto sonoro, pertenecen a diferentes estados funcionales del cerebro.

\section{El movimiento}

Ahora bien, ¿cómo funciona el movimiento? De forma coloquial podríamos decir que el movimiento corresponde a una acción del cuerpo cuando reacciona ante una situación específica ordenada por una imagen sensomotora, bien sea tomar una taza de café para desayunar, un lápiz para escribir o correr y patear un balón en un juego de fútbol, no importa la cantidad, calidad o dificultad del movimiento. Veámoslo simplemente desde el orden que sigue nuestro cerebro.

Si voy a tocar una escala y mi concepto $\mathrm{u}$ objetivo sonoro (que no son lo mismo, ya que el concepto está predeterminado por una experiencia adquirida mientras que el objetivo bien sea estilístico o propuesto por el compositor puede llegar a estar fuera del concepto del intérprete) se relaciona con un sonido metálico, bien sea por indicación del compositor o por propuesta del ejecutante, primero he de tener clara la imagen sensomotora (percepción) de dicho sonido para llegar a interpretarlo a través de la técnica, que incluye un movimiento dirigido con intensión consciente, que sería lo ideal, aunque muchas veces la múltiple repetición de movimientos inconscientes sin conceptos ni objetivos sonoros claros llevarán irremediablemente a una sufrida interpretación desde el punto de vista motor y por ende un incierto resultado artístico. 
Gráfico 1. Organización del proceso motor

\section{Percepción}

Imagen sensomotora

Sentidos

Objetivo musical

Concepto sonoro

\section{Movimiento}

Técnica

Interpretación

Fuente: elaboración propia.

Hay un paso del que casi nunca nos percatamos por hallarse dentro de los estados mentales inconscientes, y es el transcurso entre la percepción de la imagen sensomotora y el objetivo sonoro, recorrido al que llamaremos "predicción", concepto fundamental para el desarrollo de la conciencia del movimiento y pieza clave para la comprensión de esta metodología. Pongamos especial atención a este enunciado formulado por Llinás (2003), refiriéndose a la evolución del estado mental como un "instrumento que implementan las interacciones predictivas $\mathrm{y} / \mathrm{o}$ intencionales entre un organismo vivo y su medio ambiente" (p. 4). Y sigue:

Por percepción se entiende la validación de las imágenes sensomotoras generadas internamente por la información sensorial, que se procesa en tiempo real y que llega desde el entorno que rodea al animal. La base de la predicción-que es la expectativa de los eventos por venir-es la percepción. La predicción, función tan radicalmente diferente del reflejo, constituye la verdadera entraña de la función cerebral. (p. 4)

Este descubrimiento generó en mí una inquietud acerca de los procesos técnicos que se utilizan en el estudio del instrumento, y tener claros los elementos que diferencian los conceptos de predicción y reflejo permitiría cambiar algunos elementos en nuestro sistema tradicional de estudio. El reflejo es aprendido, memorizad; pero también puede ser guiado por un evento futuro, como el arquero de un partido de fútbol que se enfrenta a un delantero en el cobro de un tiro penal. Tiene reflejos memorizados, estudiados, ejercitados, pero no le garantizarán un buen resultado en el evento inminente por venir. Estos reflejos, que se denominarán Patrones de Acción Fijos (PAF), "son reflejos algo más elaborados que agrupan reflejos inferiores en sinergias (grupos de reflejos capaces de comportamientos dirigidos más complejos)" (Llinás 2003, p. 156). En este orden de ideas, nuestro gráfico núm. 1 será modificado de la siguiente manera.

Gráfico 2. La predicción en la organización del sistema motor

\section{Percepción}

Imagen sensomotora

Sentidos

Objetivo musical

Concepto sonoro

Fuente: elaboración propia.

\section{Predicción}

Eventos por venir Interpretación

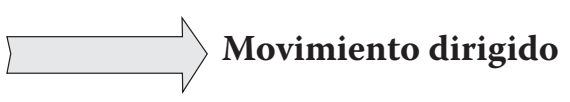

Técnica

Revista PAPELES • ISSN 0123-0670 • Vol. 9(18) • pp. 45-55 • Julio-diciembre de 2017 


\section{Técnica guitarrística como objetivo motor}

Ya hemos visto cómo funciona el movimiento desde una perspectiva neurocientífica y pasaremos a la aplicación de esos conceptos para lograr un desarrollo de la técnica y la interpretación. Es necesario tener claro que gran parte de los ejercicios o desafíos técnicos que presente una determinada obra pertenecen al funcionamiento motor de movimientos dirigidos, los cuales son controlados y factibles de ser corregidos.

Uno de los grandes retos que propone este documento es la necesidad de empezar un proceso de conciencia motriz a partir de los elementos que componen el movimiento (percepción, predicción y movimiento dirigido) y no con base en la repetición descontrolada de pasajes de obras o ejercicios técnicos. Será necesario (aunque pueda sonar un poco traumático para quienes llevan muchos años tocando con tensiones acumuladas e inconscientes) empezar de cero con un análisis de la posición inicial. Para desarrollar esta sección propondré tres conceptos que aparecen descritos por Eduardo Fernández en su libro Técnica, mecanismo, aprendizaje (2000):

- Llamaremos mecanismo al conjunto de reflejos adquiridos que hacen posible tocar la guitarra.

- Llamaremos técnica a los procedimientos a seguir a efectos de dominar un pasaje o una dificultad dados;

- Por último, llamaremos aprendizaje de mecanismo o de técnica respectivamente, al proceso de adquisición de un reflejo (en el aprendizaje del mecanismo), o del dominio de un pasaje o dificultad concretos (en el aprendizaje de la técnica). [p. 9]

En primera instancia, una de las principales dificultades que presenta la guitarra es la adaptación a una adecuada posición del cuerpo para tocar, así como los puntos de contacto con el mismo. Como veremos más adelante, el error más común en los diferentes aspectos son las tensiones musculares que van apareciendo de forma inconsciente, ya que generalmente se intenta adaptar el cuerpo al instrumento y no al contrario.

Las tensiones más comunes se presentan en espalda, hombros, brazos, antebrazos y muñecas, siendo esta última la más delicada, ya que al ser la articulación que conecta mano y brazo, influirá ampliamente en el desempeño técnico, afectando la ejecución y el sonido.

Imagen 1. Posición del cuerpo y puntos de contacto

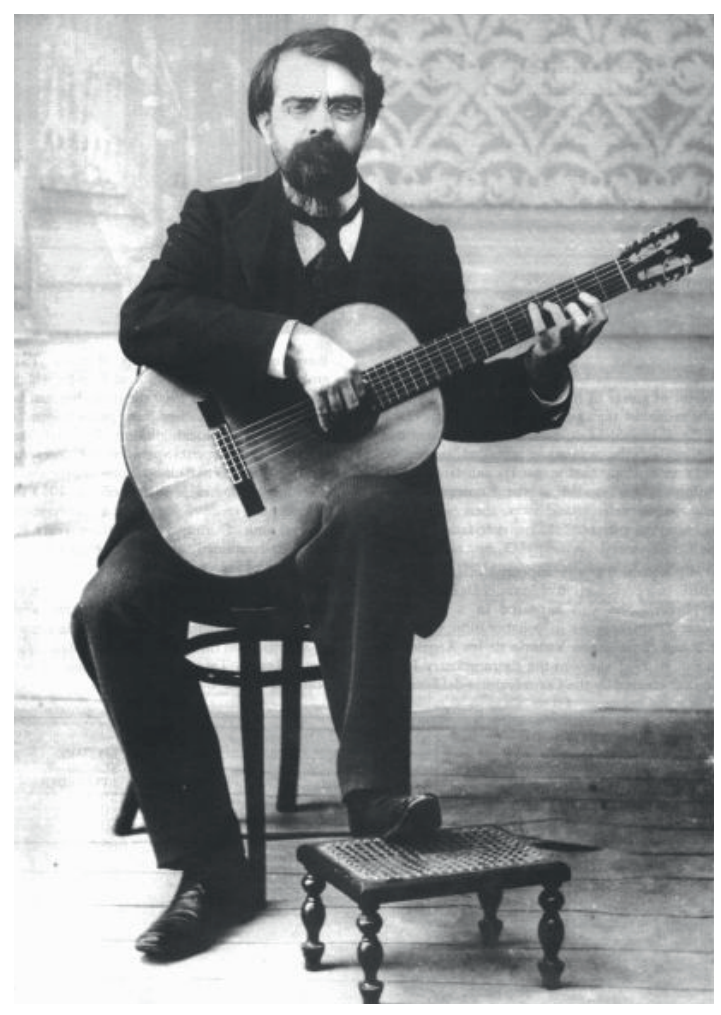

1. Pecho

2. Antebrazo derecho

3. Muslo derecho

4. Muslo izquierdo

5. Mano izquierda

6. Mano derecha

Fuente: http://inciclopedia.wikia.com/wiki/Archivo: Francisco_Tarrega_001.jpg 
Finalmente, los dos puntos de contacto más importantes que no aparecen señalados y que por obvias razones son los más importantes son los dedos de ambas manos.

Las líneas punteadas de la mano izquierda de la imagen corresponden a los grados de inclinación del instrumento con respecto al punto plano del escenario.

Como pudimos observar en la tabla núm. 1, los puntos de contacto pertenecen al concepto de percepción sensorial táctil; es decir, que lo primero que haremos será tomar consciencia de ello y determinar cuáles se presentan de forma incómoda o poco natural y concentrarnos en percibir y memorizar esa sensación.

Generalmente, las piernas no presentarán mayores tensiones, así que recomiendo empezar por la espalda, que debe estar recta y separada del espaldar de la silla. Siéntese en el borde, relaje los hombros y manténgalos en completo equilibrio. Cierre los ojos y realice un ejercicio de escanner pasando una línea imaginaria desde la base de la espalda hasta el cuello. Cuando localice una tensión (percepción), elimínela. Vuelva a pasar la línea imaginaria y podrá descubrir que encontrará tensiones que no había percibido en el primer ejercicio. Cuando encuentre esas tensiones, elimínelas. Focalice el punto (predicción) y envíele la orden de relajación (movimiento dirigido). Repita el ejercicio varias veces hasta sentirse totalmente cómodo y mantenga su atención permanente antes y durante la sesión de estudio.

El paso a seguir es la colocación de las manos en el diapasón, para lo cual recomiendo revisar la imagen 1. El codo del brazo izquierdo debe ser un peso muerto. La mano izquierda se pondrá de frente a los trastes con la punta de los dedos (táctil) en el traste $\mathrm{V}$, cuerda núm. 3, el pulgar en la mitad del brazo de la guitarra y entre dedos 1 y 2 , tal como aparece en la imagen 2.
Imagen 2. Posición de mano izquierda

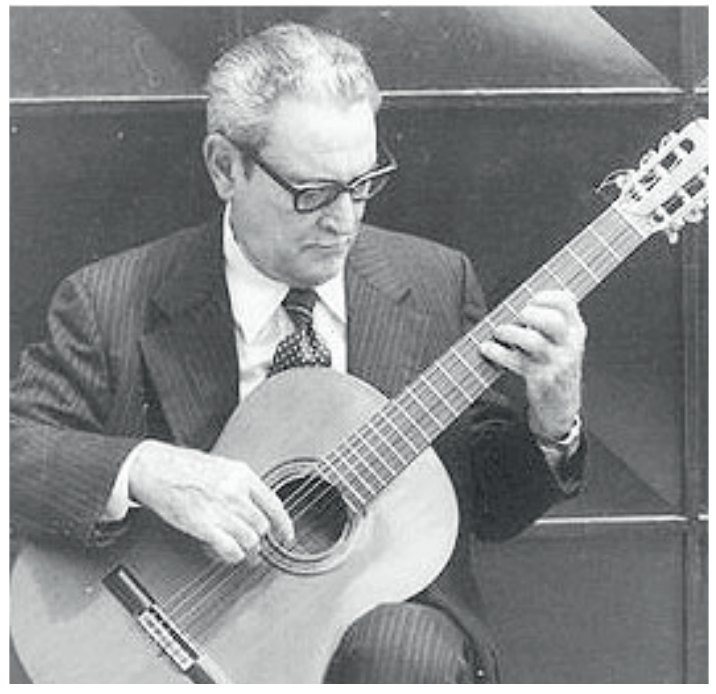

Fuente: https://paratocarguitarra.wordpress.com

Esta es una posición base que funcionará en cualquier parte del diapasón hasta el traste 9. Realice el mismo ejercicio que se hizo con la espalda, pero ahora la línea imaginaria recorrerá desde el hombro hasta la punta de los dedos. Sugiero especial cuidado con este ejercicio, ya que incluye el recorrido por varias articulaciones importantes que pueden generar tensiones que dificultarán el mecanismo para mejorar la técnica. De nuevo recomiendo memorizar la sensación de la mano con la mayor relajación posible, cualquier cambio en la posición o en la falta de control al aplicar la fuerza generará tensiones. Si percibe alguna dificultad, ubique primero la tensión (táctil), corrija mentalmente la posición e imagínela en estado de reposo (predicción), luego envíe la orden y corrija (movimiento dirigido).

Para la posición de mano derecha me apoyaré en el texto de Fernández (2000):

La construcción detallada de la posición del brazo requiere decidir previamente sobre algunas opciones básicas. Dos de las más fundamentales son si se debe atacar las cuerdas con las uñas o con las yemas de los dedos, y en qué ángulo deberán los dedos atacar las cuerdas. (p. 21) 
El desarrollo del sonido está a cargo de la mano derecha y merecería un capítulo aparte porque implicaría la explicación, el análisis y un discurso metodológico para el desarrollo intelectual del intérprete y una construcción de un concepto sonoro basado en diferentes marcos históricos, audiciones, géneros, estilos y propuestas compositivas, que requieren un análisis aún más profundo y más detallados de estos mismos conceptos neuromotores. Así que me referiré únicamente a los elementos fundamentales, ya que si se logran asimilar desde el punto de partida será más fácil su aplicación en situaciones interpretativas más complejas.

Volviendo a la posición de la mano derecha, Fernández (2000) continúa:

Esto requerirá que la mano derecha quede en una posición similar a la que adoptaría para agarrar un tubo cilíndrico, con los dedos índice, mayor, anular y meñique siguiendo la curva del tubo, y con el pulgar apoyado en el centro del mismo, en la superficie superior. De acuerdo a esto, la acción de índice, mayor y anular se realizará hacia la palma de la mano y el pulgar actuará atacando la cuerda aproximadamente con su esquina inferior izquierda (con uña, yema $u$ opcionalmente una u otra según la forma escogida por el ejecutante de limar esa uña). En este caso, todas las acciones de ataque harán vibrar las cuerdas predominantemente en un plano básicamente paralelo a la tapa. Una línea que pase por la articulación entre la mano y los dedos, o sea, por lo nudillos quedará así colocada en un plano paralelo a la tapa. (pp.19-20)

Las principales dificultades mecánicas que se presentan son la mala ubicación de la muñeca y las tensiones en el hombro que alteran la operatividad y eficacia de todo el mecanismo, así que será necesario en algunos casos reconstruir la posición. Primero revise nuevamente su hombro, debe estar totalmente relajado. Luego apoye el antebrazo en el aro superior teniendo en cuenta la longitud del mismo, de modo tal que la mano quede cómodamente a la altura de las cuerdas y fuera de la boca. Relaje la mano derecha y déjela caer como un peso muerto. Memorice esa sensación de relajación de su mano y lentamente, sin perder control de tensiones, colóquela sobre las cuerdas. Este movimiento y consecuente cambio de posición no debe generar tensión ni en hombro ni en muñeca.

En cuanto a la producción del sonido me centraré en aspectos globales. La uña debe estar correctamente limada conforme a como el maestro haya indicado. El ataque puede ser libre o apoyado y la mano no deberá cambiar de posición en un ejercicio inicial. La acción del dedo debe ir hacia la palma de la mano y tan pronto se produzca el sonido el dedo que ejecutó debe volver de forma natural a su estado de reposo, es decir, a la posición inicial para volver a repetir este movimiento las veces necesarias, esto para lograr una mayor proyección. El ejercicio de consciencia consiste en imaginar un punto específico, preferiblemente lejano del recinto donde está estudiando. Cree una imagen sensorial auditiva (de volumen) y táctil (de acción del dedo y el contacto con la cuerda) y direcciónela a ese punto que escogió (predicción). Realice el movimiento como se explicó anteriormente (movimiento dirigido). Lo ideal es lograr el objetivo y mejorar la proyección de sonido, ya que al estudiar se centra la atención generalmente en lograr superar los pasajes difíciles y en ocasiones se dejan de lado aspectos sustanciales.

Si el objetivo es calidad de sonido el ejercicio será diferente y para ello será necesario tener un concepto sonoro definido a través de la percepción auditiva. En este caso influirá no solo el limado de la uña y el ataque sino la idea preconcebida de sonido que se quiere obtener (predicción).

En resumen, es importante partir de una posición correcta del instrumento y una adecuada utilización de las dos manos y los mecanismos 
que intervienen en cada movimiento. De cada aspecto técnico es primordial determinar un punto de partida para generar un movimiento correcto que produzca buenos resultados musicales. El punto 0 es la relajación y la consciencia que se debe tener de ella. Luego se escogerá el elemento de percepción sensorial a utilizar. En seguida se pondrá un objetivo delimitado por elementos compositivos de las obras o conceptos sonoros del intérprete (predicción). Por último, se ejecutará el movimiento con intención (movimiento dirigido).

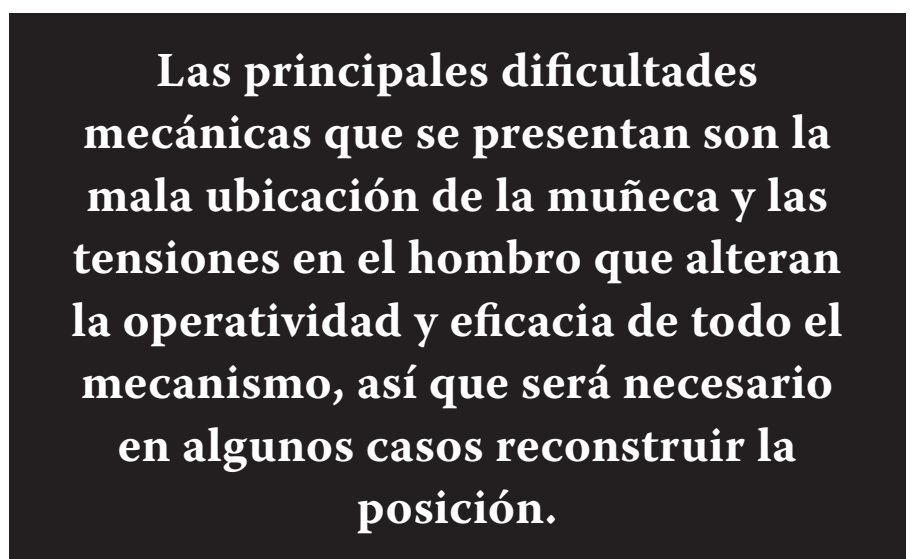

\section{Ejemplos específicos}

Una vez que tenemos claro cómo conscientizar una posición y un accionar de las dos manos me permito citar algunos ejemplos de cómo se puede aplicar a pasajes específicos de obras y estudios donde aparezcan los principales elementos técnicos de la interpretación guitarrística, entre ellos, el arpegio, el ligado y el acorde "plaqué" (sonido de dos o más voces de un acorde de forma simultánea).

\section{Acordes plaqué y arpegios}

Este es un fragmento de un método del compositor italiano Mauro Giuliani que incluye acordes plaqué (1) y arpegios (2). La idea es cumplir un objetivo con una cantidad mínima de repeticiones y para ello se seguirá nuevamente le proceso neuromotor sugerido.
El objetivo para el sistema 1 es lograr el equilibrio en todas las voces de acorde y lograr destacar dentro un mismo ataque (las tres simultáneamente), una sola voz de entre las demás. El procedimiento a seguir de acuerdo al texto es identificar percepciones sensoriales. Lo primero es que, como ya se dijo anteriormente, la producción del sonido depende en gran parte de la mano derecha, así que me enfocaré en ella. Para destacar una voz de entre las demás es pertinente saber que pertenece a dos percepciones: auditiva y táctil. Lo primero es tener una imagen clara de la sensación de movimiento del dedo que ejecutará y resaltará esa nota (p. táctil). Es ideal que el intérprete sepa discriminar de entre las tres voces la que quiere resaltar y tenerla clara en su mente como una imagen sonora

Imagen 3. Estudios 1 y 2 Op. 1 de Mauro Giuliani (fragmento)

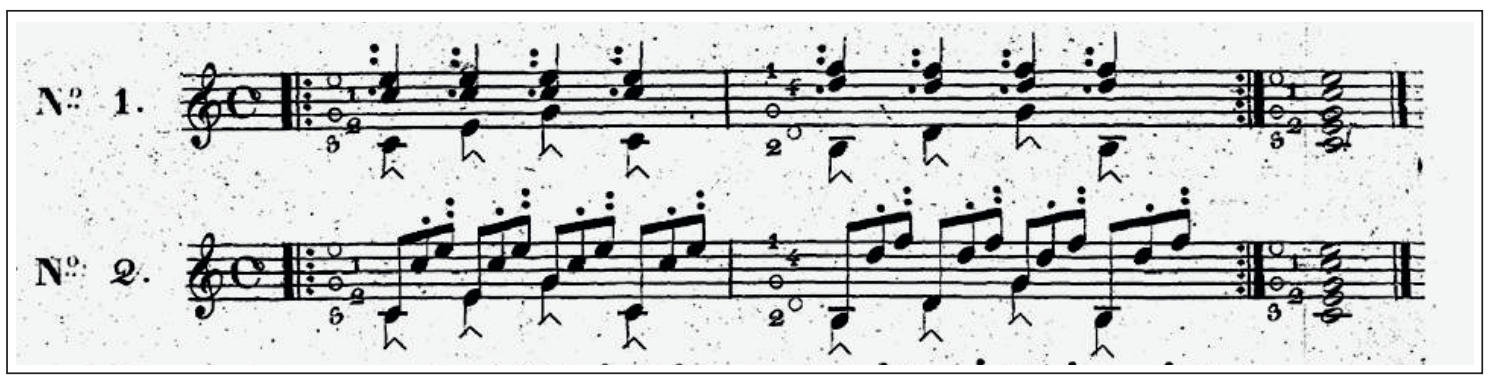

Fuente: Petrucci Music Library https://imslp.org. 


\section{Se pueden buscar varias formas}

de estudiar un pasaje, incluso se

podrían estudiar los arpegios desde

el punto de vista de la tímbrica,

la frase o las dinámicas,

y se necesitarían otras estrategias

que el estudiante mismo puede

desarrollar teniendo en cuenta el procedimiento que se ha propuesto.

(p. auditiva y predicción). Tocar el acorde y percibir el resultado (movimiento dirigido). Es muy importante que primero se haga la interiorización de las imágenes sensomotrices, que se determine el objetivo sonoro y luego se realice el movimiento, de lo contrario se seguiría cayendo en el método tradicional de ensayo y error. Aquí está la verdadera diferencia en esta propuesta metodológica. Se repetirá tantas veces como sea necesario, pero si algún procedimiento no está suficientemente sólido como imagen sensomotriz el ejercicio tardará más en dar resultado.

Para los arpegios me enfocaré en el aspecto de peso para destacar la primera nota de cada grupo de tresillos que estará a cargo del dedo pulgar. Recomiendo antes de iniciar tener una correcta posición de la mano derecha y ser muy disciplinado con el razonamiento de relajación del cuerpo y las manos. Se hará una imagen sensomotriz de que el dedo pulgar es muy pesado (p. táctil) y que el ataque de esta nota es la causa y las dos siguientes del tresillo, la consecuencia (predicción). Se hará luego lo mismo no solo con cada grupo de tresillos sino con la frase completa; esto permitirá que la ejecución suene más ligada. Realice el movimiento y perciba el resultado, antes de volverlo a intentar analice qué faltó o qué falló en el procedimiento. Estos tiempos de análisis, percepción y resultados positivos se lograrán cada vez con mayor facilidad.
Se pueden buscar varias formas de estudiar un pasaje, incluso se podrían estudiar los arpegios desde el punto de vista de la tímbrica, la frase o las dinámicas, y se necesitarían otras estrategias que el estudiante mismo puede desarrollar teniendo en cuenta el procedimiento que se ha propuesto.

\section{Los ligados}

Para finalizar, pongo otro ejemplo de un aspecto técnico que se convierte en una dificultad muy común: los ligados. Varios compositores se enfocaron en escribir gran cantidad de estudios que permiten trabajar este elemento de diversas formas. He tomado como ejemplo el Estudio núm. 3 del compositor brasileño Heitor Villa-lobos y presenta varias dificultades, no simplemente los ligados sino también los desplazamientos del antebrazo. El principal problema al que se enfrentará el intérprete será mantener correcta la posición de la mano izquierda en los desplazamientos, ya que si la mano no llega de forma frontal los ligados fallarán y la pieza se echará a perder tanto en su objetivo para el intérprete como la música para quien lo escucha.

De modo que lo primero que se trabajará serán los desplazamientos del antebrazo. se hará una imagen sensomotriz del desplazamiento (visual) y memorizará el recorrido de la mano, su posición de salida y su punto de llegada teniendo en cuenta que los dedos caigan correctamente y frontal al diapasón, es muy importante tener clara la imagen táctil del punto de contacto de la punta de los dedos

Imagen 4. Estudio núm. 3 de Heitor Villa-lobos (fragmento)

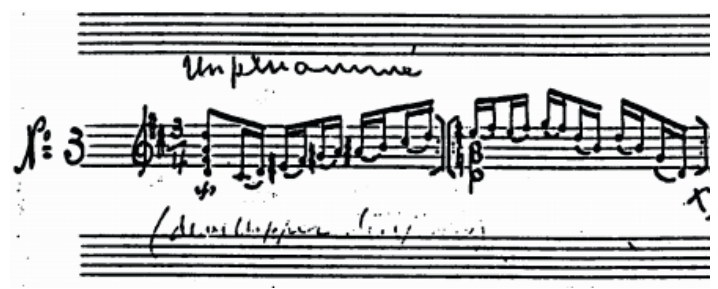

Fuente: Petrucci Music Library https://imslp.org 
sobre las cuerdas, esto facilitará la fijación de la imagen para los desplazamientos. Luego se realizarán los ligados y se procederá a realizar el movimiento. Se hará lentamente y con articulación muy clara antes de desarrollar la velocidad real del estudio. Luego del primer intento se percibirá el resultado y se analizarán los aspectos a mejorar, de seguro se reducirán el número de repeticiones que normalmente serían necesarias para lograr el objetivo.

En conclusión, lo que pretende este texto es realizar una propuesta metodológica para enfrentar los problemas técnicos desde un punto de vista diferente tomando como referencia los descubrimientos realizados en neurociencia y aplicarlos en el abordaje de diferentes obras y el montaje de repertorio para un examen o un concierto de guitarra. Se trataron temas fundamentales, ya que, como dije anteriormente, cuando se superen, será mejor aplicarlos en pasajes musicales de mayor complejidad. Espero que este documento permita al guitarrista mejorar en sus aspectos motores a través del manejo del movimiento consciente y razonado, que promueva el análisis y la reflexión, que les ayude a ahorrar tiempo y energía, y sobre todo. un mayor dominio del instrumento que les incentive a permanecer motivados y realizar mejores interpretaciones.

\section{Referencias}

Fernández, E. (2000). Técnica, mecanismo, aprendizaje. Montevideo (Uruguay): Ed. ART.

Llinás, R. (2003). El cerebro y el mito del yo. Bogotá (Colombia): Ed. Norma. 